\title{
Tunable aziridinium ylide reactivity: non-covalent interactions enable divergent product outcomes.
}

Kate A. Nicastri, ${ }^{1}$ Soren A. Zappia, ${ }^{1}$ Jared C. Pratt, ${ }^{1}$ Julia M. Duncan, ${ }^{1}$ Ilia A. Guzei ${ }^{1}$, Israel Fernández $^{2, *}$ and Jennifer M. Schomaker ${ }^{1, *}$

${ }^{1}$ Department of Chemistry, University of Wisconsin, 1101 University Avenue, Madison, WI 53706

${ }^{2}$ Departamento de Química Orgánica I and Centro de Innovación en Química Avanzada (ORFEO-

CINQA), Facultad de Ciencias Químicas, Universidad Complutense de Madrid, 28040-Madrid,

Spain

KEYWORDS aziridine, aziridinium ylide, carbene, morpholine, tunability, non-covalent interactions

\begin{abstract}
Methods for rapid preparation of densely functionalized and stereochemically complex $N$ heterocyclic scaffolds are in demand for exploring potential new bioactive chemical space. This work describes experimental and computational studies to better understand the features of aziridinium ylides as intermediates for the synthesis of highly substituted dehydromorpholines. The development of this chemistry has enabled the extension of aziridinium ylide chemistry to the concomitant formation of both a $\mathrm{C}-\mathrm{N}$ and a $\mathrm{C}-\mathrm{O}$ bond in a manner that preserves the stereochemical information embedded in the substrate. The chemistry is tolerant of a wide range of functionalities that can be employed for DNA-encoded library (DEL) synthesis to prepare diverse libraries of heterocycles with potential bioactivity. In addition, we have uncovered several key insights that describe the importance of steric effects, rotational barriers around the $\mathrm{C}-\mathrm{N}$ bond of the aziridinium ylide, and non-covalent interactions (NCIs) on the ultimate reaction outcome.
\end{abstract}


These critical insights will assist in the further development of this chemistry to generate novel and complex $N$-heterocycles that will further expand complex amine chemical space.

\section{INTRODUCTION}

Onium ylides ${ }^{1-5}$, including sulfur ${ }^{6 \mathrm{a}-\mathrm{d}}$, oxonium $^{7}$ and ammonium, $^{8 \mathrm{a}, \mathrm{b}}$ are common intermediates employed in the syntheses of complex molecules. They are typically generated from the reaction of a heteroatom with a metal-supported carbene to furnish reactive zwitterionic intermediates that engage in a diverse set of reaction pathways, including 1,2-Stevens rearrangements, ${ }^{8 \mathrm{~b}} 2,3$-sigmatropic rearrangements, ${ }^{9}$ and $\mathrm{N}-\mathrm{H}$ insertion reactions (Scheme 1A). ${ }^{3}$ The aziridinium ylides ${ }^{10}$ represent a unique subclass of ammonium ylides whose reactivity is both poorly understood and underexplored, despite the potential for these reactive species to serve as key intermediates in the transformation of simple precursors to densely functionalized, stereochemically rich $N$-heterocycles. We are interested in applying the ability to shuttle aziridinium ylides along divergent pathways to explore diverse new amine chemical space, particularly in the context of using our new methods for the preparation of DNA-encoded libraries (DEL) to explore their potential bioactivity. ${ }^{11 \mathrm{a}-\mathrm{c}}$

Manipulating the reactivity of aziridinium ylides to achieve a desired reaction outcome can be challenging as compared to their acyclic ammonium counterparts. Aziridinium ylides are embedded in a highly strained ring, where the bonding constraints of the aziridine increase the energy required for pyramidal inversion of the nitrogen; often this rate is slow enough to measure using variable temperature (VT) or dynamic NMR spectroscopy. ${ }^{12 \mathrm{a}-\mathrm{c}}$ The presence of two invertomers hinders the ability to selectively form and engage aziridinium ylides in secondary reactions and has limited their applications in the synthesis of complex $N$-heterocycles. For 
example, in 2001 and 2004 respectively, Clark ${ }^{13}$ and Rowlands ${ }^{14}$ observed intramolecular [2,3]Stevens rearrangements of aziridinium ylides to deliver dehydropiperidines in low 21-24\% yields (Scheme 1B). In the former case, the low yield was attributed to the instability of the starting material which decomposed in one day when stored under argon at $-30{ }^{\circ} \mathrm{C} .{ }^{13}$ In Rowland's work, the alkyl aziridine substrate existed as two $N$-invertomers $\mathbf{a}$ and $\mathbf{b}$ in a ratio of $3: 4$, with an estimated barrier to $N$-inversion at room temperature of $\sim 16-20 \mathrm{kcal} / \mathrm{mol}$. Only a possessed the required geometry for the desired rearrangement; as a result, the major invertomer b underwent an unproductive 1,5-hydride shift at a faster rate than $N$-inversion to generate the invertomer required for the desired reactivity. ${ }^{14}$ In addition to the formation of invertomers of the aziridinium ylide, competitive cheletropic extrusion renders the use of these intermediates in selective transformations particularly challenging. ${ }^{15}$

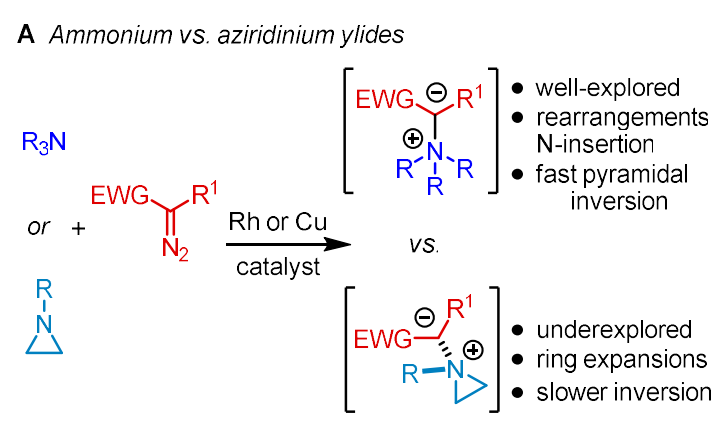

D This work: Divergent and tunable reactivity<smiles>[R]C1=C([R])N2C(=O)OCC[C@H]2[C@H]([R1])O1</smiles>

- features of aziridinium ylides that yield divergent reactivity

- new amine chemical space for DNA-encoded libraries

- mechanistic insights

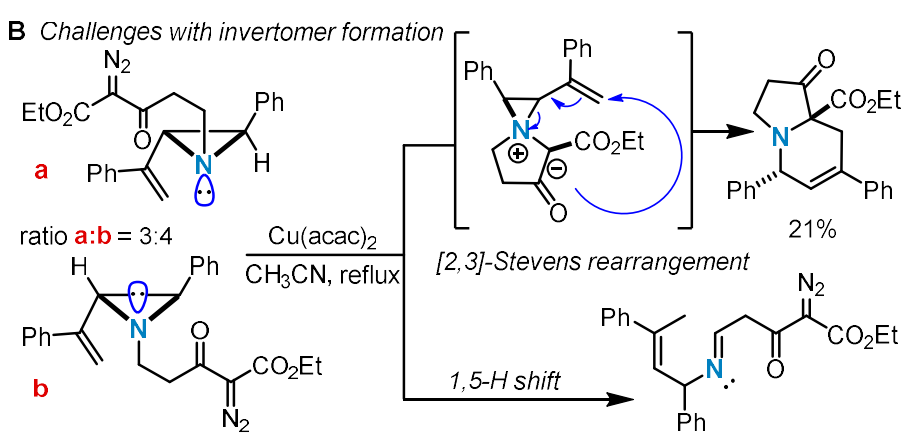

C Solving the invertomer problem Schomaker (2017)

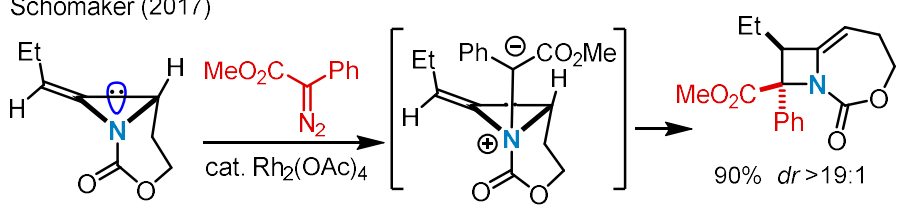

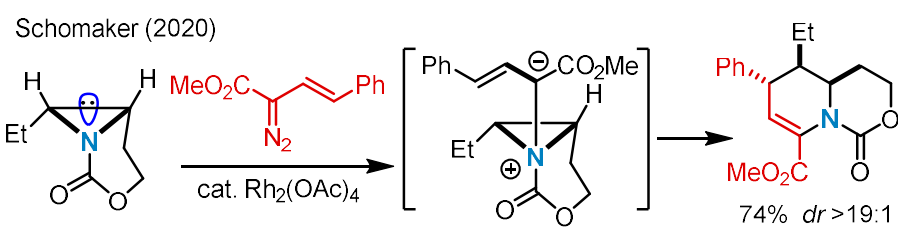

Scheme 1. Prior work in aziridinium ylide chemistry and new divergent reactivity. 
We used rigid bicyclic aziridines (Scheme 1C), generated via silver-catalyzed nitrene transfer of homoallenic and homoallylic carbamates, as precursors to aziridinium ylides. ${ }^{16 a-c}$ The nitrogen of the carbamate tether in the bicyclic aziridine possesses a hybridization of $\sim \mathrm{sp}^{3}$, where the nitrogen lone pair is unable to engage in effective orbital overlap with the $\pi$-system of the carbonyl group. As a result, the carbamate behaves as a $\sigma$-electron-withdrawing group and raises the barrier to $\mathrm{N}$-pyramidal inversion. ${ }^{17}$ The geometric constraint imposed by the bicyclic nature of the tether also raises the nitrogen inversion barrier; ${ }^{17}$ a similar effect is observed in rigid cyclic amines such as sparteine and Tröger's base. ${ }^{18,19}$ Both of these unique structural characteristics can be exploited to generate diastereomerically pure aziridinium ylides that ultimately furnish highly substituted methyleneazetidines ${ }^{20 \mathrm{a}-\mathrm{b}}$ and dehydropiperidines ${ }^{21}$ in excellent yield and $d r$ (Scheme 1C). This strategy effectively circumvents competing pathways that have been observed in previous attempts to leverage the reactivity of aziridinium ylides. However, despite this progress, the future development of productive chemistry of aziridinium ylides requires a more detailed understanding of how the identity of the carbene precursor, potential dynamic behavior in the ylide intermediate and non-covalent interactions influence the ultimate outcome of the reaction. In this work, we describe our mechanistic findings to explain divergent reaction pathways from aziridinium ylides generated by leveraging ketone-containing carbenes, derived from Rh catalysis, to furnish fully substituted dehydromorpholines (Scheme 1D). ${ }^{22-24}$ Both experimental and computational studies are presented that will inform future efforts of our and other groups' work on these fascinating and versatile reactive species.

\section{Results and discussion}

Initial explorations of diverse carbene precursors. We first investigated whether the carbonyl oxygen of a donor-acceptor diazoketone, such as $\mathbf{2 a}$, could serve as a competent nucleophile to 
open the aziridinium ylide en route to a dehydromorpholine (Scheme 2A). Only one nucleophilic ketone group is present in $\mathbf{2 a}$; thus, we expected reaction of $\mathbf{2 a}$ with $\mathbf{1}$ to furnish $\mathbf{4 a}$ in good yield via conformer INT1. Surprisingly, treatment of $\mathbf{1}$ with $\mathbf{2 a}$ under $\mathrm{Rh}_{2}(\mathrm{OAc})_{4}$ catalysis gave an unusual [3,9]-aziridine product 3a in $78 \%$ yield. Presumably, the $7 \mathrm{kcal} / \mathrm{mol}$ barrier to interconversion of aziridinium ylide INT1 to INT2 via rotation around the $\mathrm{C}-\mathrm{N}$ bond (Figure 2,

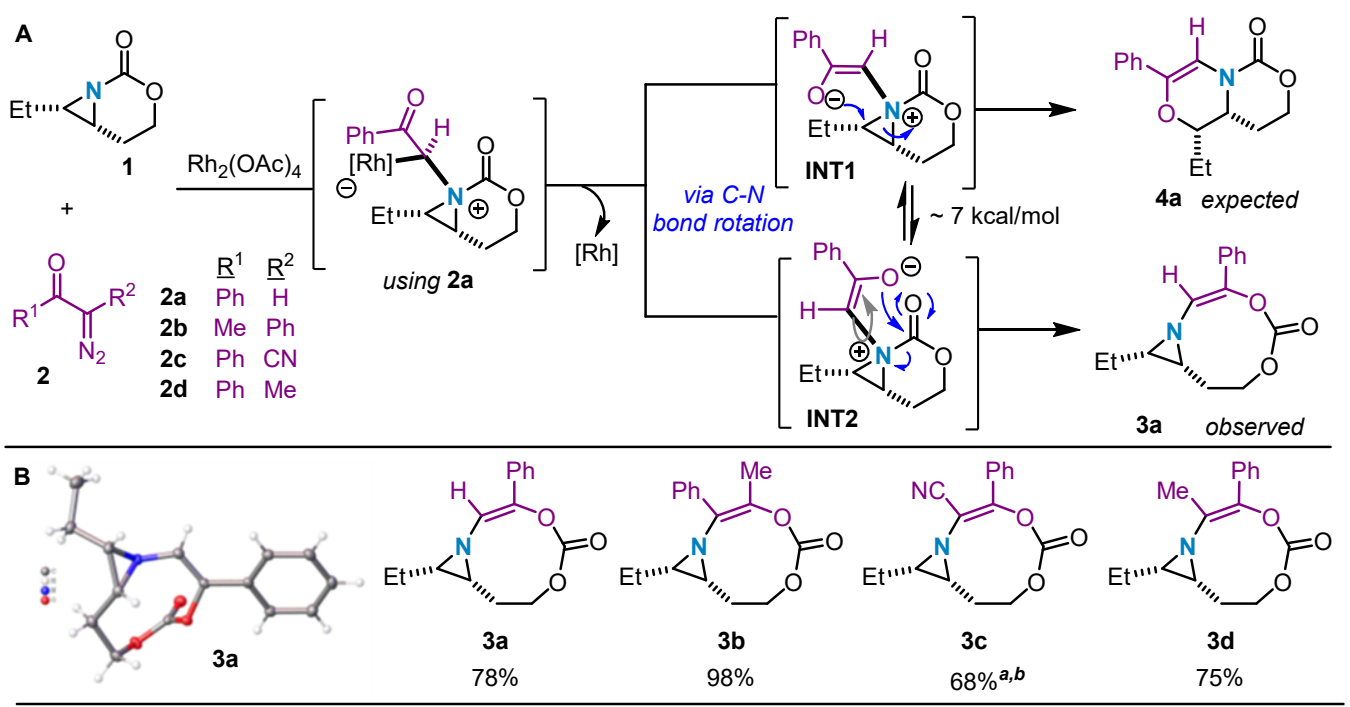

Standard conditions: Slow addition of the diazoketone (3.0 equiv) over $3 \mathrm{~h}$ to a mixture of $3 \mathrm{~mol} \% \mathrm{Rh}_{2}(\mathrm{OAc})_{4}$ and aziridine (1.0 equiv) in $\mathrm{CH}_{2} \mathrm{Cl}_{2}$ at $40{ }^{\circ} \mathrm{C}$. Yields are given for isolated products. ${ }^{a}$ Yields determined by ${ }^{1} \mathrm{H}$ NMR using $1,3,5-$ trimethoxy-benzene as an internal standard. ${ }^{b} \mathrm{~A}$ small amound of $4 \mathrm{c}(19 \%)$ was also detected in this crude $\mathrm{H}$-NMR spectrum

Scheme 2. Ring expansions of $\mathbf{1}$ with donor-acceptor diazoketone carbene precursors.

vide infra) enables nucleophilic attack of the ketone oxygen on the carbonyl of the carbamate tether to furnish 3a. This result was unexpected, as nucleophilic addition to the carbamate tether was not observed in previous syntheses of azetidines or dehydropiperidines from bicyclic aziridines. ${ }^{20 a b, 21}$

We were curious as to the origin of $\mathbf{3 a}$ and surmised it might arise from a non-covalent interaction (NCI) in the aziridinium ylide intermediate INT2 that biases the reaction towards this unexpected product. Helliwell and co-workers reported evidence for NCIs between carbonyls and aromatic $\pi$-electron clouds; we wondered if a similar interaction between the ketone phenyl group and the carbamate carbonyl group might be operative in the transition state. ${ }^{25}$ However, 
exchanging the Ph group of $\mathbf{2 a}$ to a Me group in $\mathbf{2 b}$ still furnished $\mathbf{3 b}$ in an excellent $98 \%$ yield. Altering the electronics of $\mathrm{R}^{2}$ had no effect on product selectivity. Both electron-withdrawing and donating substituents (e.g. $\mathrm{CN}$ in $\mathbf{2 c}$, Me in 2d) furnished the [3,9]-aziridine in $75 \%$ (3d) and $68 \%$ (3c) yields, respectively. The consistent product outcome suggested that neither $\mathrm{R}^{1}$ nor $\mathrm{R}^{2}$ engages in NCIs with the carbamate group to influence the preferred formation of the $[3,9]$-aziridine product.

To gain more insight into the formation of $\mathbf{3 a}$ at the expense of the expected bicyclic $\mathbf{4 a}$, Density Functional Theory (DFT) calculations were carried out at the dispersion-corrected $\operatorname{SMD}\left(\mathrm{CH}_{2} \mathrm{Cl}_{2}\right)$-B3LYP-D3/def2-SVP level (see computational details in the Supporting Information). Figure 1A shows the computed rection profiles leading to the formation of the $\mathbf{3 a}$ and 4a from the corresponding free aziridinium ylides, which according to our previous calculations on related systems, ${ }^{20 b, 21}$ derives from the nucleophilic addition of the aziridine $2 \mathbf{a}$ to the $\mathrm{Rh}_{2}$-carbene intermediate (formed upon reaction of the diazo-compound and $\left.\mathrm{Rh}_{2}(\mathrm{OAc})_{4}\right)$. From the data in Figure 1A, it becomes evident that metal-free ylide INT2 involved in the [3,9]pathway is lower in energy than its analogous intermediate INT1 involved in the alternative [6,6]pathway $(-4.2 \mathrm{kcal} / \mathrm{mol})$. A similar finding was observed in their metal-ylide counterparts $(\Delta \Delta \mathrm{G}$ $=-5.7)$. According to the NCIPLOT method, this is in part ascribed to the occurrence of a stabilizing NCI involving the $\mathrm{C}-\mathrm{O}$ lone pair of the ketone moiety and the $\pi^{*}(\mathrm{C}=\mathrm{O})$ molecular orbital of the carbamate, as confirmed for INT2 (Figure 1B; see also Figure S-14 in the Supporting Information for the metal-ylide intermediate INT2-Rh). The presence of this stabilizing NCI is also supported by the computed short $\mathrm{O} \cdots \mathrm{C}(=\mathrm{O})$ distance in INT2 of $2.530 \AA$, which is markedly shorter than the sum of the van der Waals radii (3.22 $\AA$ ); this was also confirmed by the associated stabilization energy $\left(\Delta \mathrm{E}^{(2)}=-6.63 \mathrm{kcal} / \mathrm{mol}\right)$ computed for the lone pair $(\mathrm{LP})(\mathrm{O}) \rightarrow \pi^{*}(\mathrm{C}=\mathrm{O})$ 

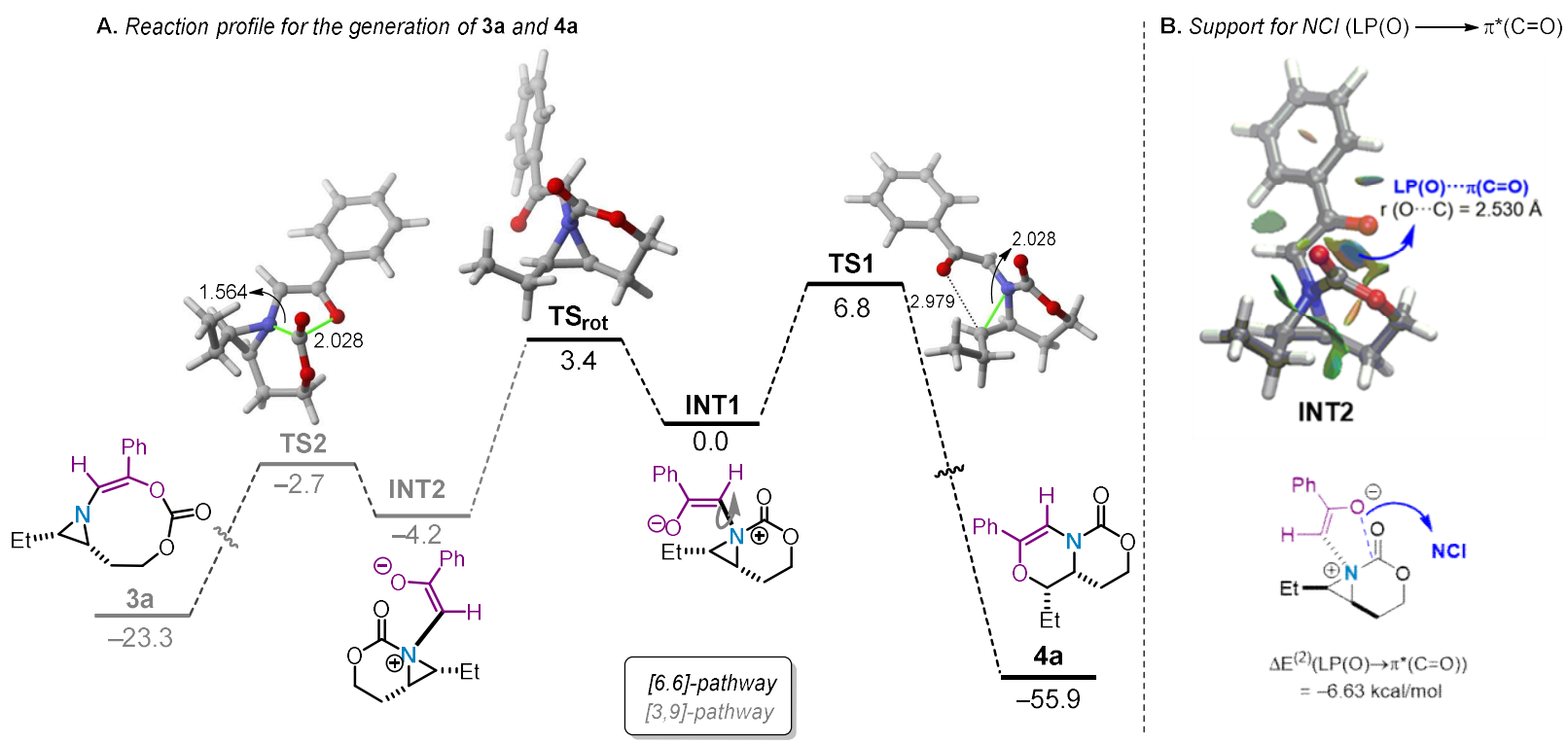

Figure 1. A. Computed reaction energy profiles for formation of 3a and 4a. Relative free energies $\left(\Delta \mathrm{G}_{298}\right.$, at $298 \mathrm{~K}$ ) and bond distances are given in $\mathrm{kcal} / \mathrm{mol}$ and angstroms, respectively. B. Contour plots (left) of the reduced density gradient isosurfaces (density cutoff of 0.04 a.u.) for intermediate INT2. The green surfaces indicate attractive noncovalent interactions. Associated SOPT-NBO stabilizing energy (right). All data have been computed at the $\operatorname{SMD}\left(\mathrm{CH}_{2} \mathrm{Cl}_{2}\right) \mathrm{B} 3 \mathrm{LYP}-\mathrm{D} 3 /$ def2-SVP level of theory.

interaction using the Second-Order Perturbation Theory (SOPT) of the NBO method (Figure 1B). Furthermore, the barrier associated with the formation of 3a from INT2 is $5.3 \mathrm{kcal} / \mathrm{mol}$ lower than that associated with the formation of 4a from INT1 (Figure 1A). This noticeable difference in the calculated activation energies for the two potential reaction pathways and the occurrence of the NCIs, which stabilize the key ylide intermediates, lead to the preferred formation of $\mathbf{3 a}$ over $\mathbf{4 a}$, despite the fact that the latter species is significantly favored thermodynamically. The barrier to interconversion between INT1 and INT2 $(7.6 \mathrm{kcal} / \mathrm{mol}$, Figure $1 \mathrm{~A})$ is reinforced by the lower barrier $\left(\Delta \mathrm{G}^{\neq}=1.5 \mathrm{kcal} / \mathrm{mol}\right)$ computed for the generation of the observed product $\mathbf{3 a}$.

Controlling product outcomes with temperature. Changing the carbene precursor to the $\mathrm{CN}$ containing diazoketone 2c provided the first example of divergence between dehydromorpholine 4c and the [3,9]-aziridine 3c. Standard reaction conditions furnished 3c in 68\% yield (by NMR), accompanied by $19 \%$ of the dehydromorpholine $4 \mathbf{c}$ (Scheme $3 \mathrm{~A}$, right). This $3.6: 1$ ratio of $3 \mathbf{c}: 4 \mathbf{c}$ 
led us to employ computations to probe whether an NCI was also present in the corresponding aziridinium ylide and to estimate the barrier to $\mathrm{C}-\mathrm{N}$ bond rotation. Computational analysis confirmed the presence of an NCI, where the $\mathrm{O} \cdots \mathrm{C}(=\mathrm{O})$ distance of INT4 is predicted to be 2.619 $\AA$ (Scheme 3B compared to $2.530 \AA$, Figure 1B), with a stabilizing interaction energy of $\Delta \mathrm{E}^{(2)}=$ $-4.44 \mathrm{kcal} / \mathrm{mol}$. The balance between the computed barrier to $\mathrm{C}-\mathrm{N}$ bond rotation between INT3 and INT4 of $12.5 \mathrm{kcal} / \mathrm{mol}$ and the presence of an NCI leads to a divergent reaction where both $\mathbf{3 c}$ and $\mathbf{4 c}$ are accessible. These computational observations are reflected in the calculated reaction profile (Scheme 3B), where both the activation energy barriers leading to $\mathbf{3 c}$ and $\mathbf{4 c}$ are accessible ( $\Delta \mathrm{G}^{\neq} \sim 8.5 \mathrm{kcal} / \mathrm{mol}$ ), but slightly higher than that of $\mathbf{3 a}$ (Figure 1, vide supra). This higher barrier to $\mathrm{C}-\mathrm{N}$ bond rotation (compared to the analogous ylide INT2) is likely a result of charge delocalization across the $\mathrm{CN}$ group (as compared to the ketone in INT2); nonetheless, it is still low enough to ultimately give rise to the product distribution based on temperature.

The computed reaction profile depicted in Scheme 3C also shows that the NCI-stabilized ylide INT4 can undergo a cheletropic extrusion reaction to form the alkene 5c. We hypothesized running the reaction at higher temperatures would: (i) enable facile bond rotation and lead to a greater preference for $\mathbf{4} \mathbf{c}$ over the [3,9]-aziridine product $3 \mathbf{c}$ and (ii) allow access to the cheletropic extrusion product. To our delight, repeating this reaction at $83{ }^{\circ} \mathrm{C}$ in 1,2-dichloroethane (Scheme $3 \mathrm{~A}$, left) favored dehydromorpholine $4 \mathbf{c}$ formation in $50 \%$ yield by ${ }^{1} \mathrm{H}-\mathrm{NMR}$ ( $47 \%$ isolated), with the remaining mass balance (45\% yield) accounted for by formation of $\mathbf{5 c}$; no [3,9]-aziridine $\mathbf{3 c}$ formation was observed. Although full selectivity for $\mathbf{4} \mathbf{c}$ would be optimal, this reaction represents the first example where the fate of the aziridinium ylide can be controlled by the reaction conditions and not just the identity of the carbene precursor. 
A. Control over the intermediate aziridinium ylide

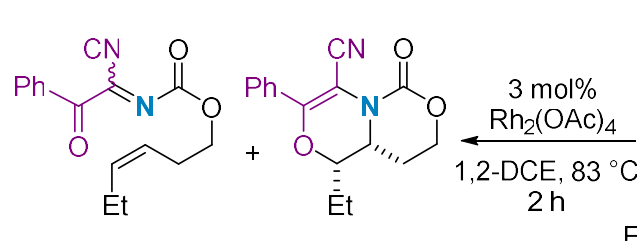<smiles>CC[C@H]1OC(c2ccccc2)=C(C#N)N2C(=O)OCC[C@H]12</smiles>
$45 \%$ a,b $5 c$ $50 \%(47 \%)^{a, b} 4 \mathrm{c}$ $E t \cdots+v_{\prime \prime,}^{N}{ }_{1}$

$68 \%{ }^{\mathrm{C}} 3 \mathrm{c}$

$19 \%{ }^{\mathrm{C}} \mathbf{4 c}$

a Yields determined by ${ }^{1} \mathrm{H}-\mathrm{NMR}$ using $10 \mu \mathrm{L}$ of mestiylene as an internal standard. ${ }^{\mathrm{b}}$ Isolated yield. ${ }^{\mathrm{C}}$ Yields determined by ${ }^{1} \mathrm{H}$-NMR using 1,3,5-trimethoxybenzene as an internal standard.

B. Proposed $\mathrm{NCl}$ in INT4 and reaction energy profile $40^{\circ} \mathrm{C}: 68 \% 3 \mathrm{c} ; 19 \% 4 \mathrm{c}$ $83^{\circ} \mathrm{C}: 50 \%$ 4c; $45 \% 5 \mathrm{c}$
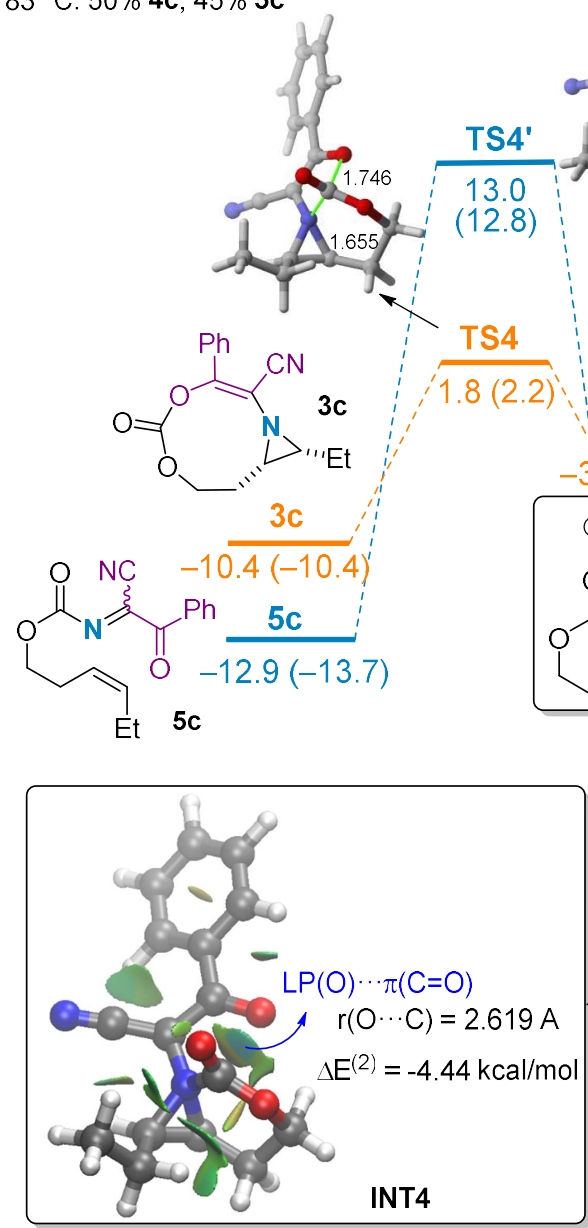

file

(1)
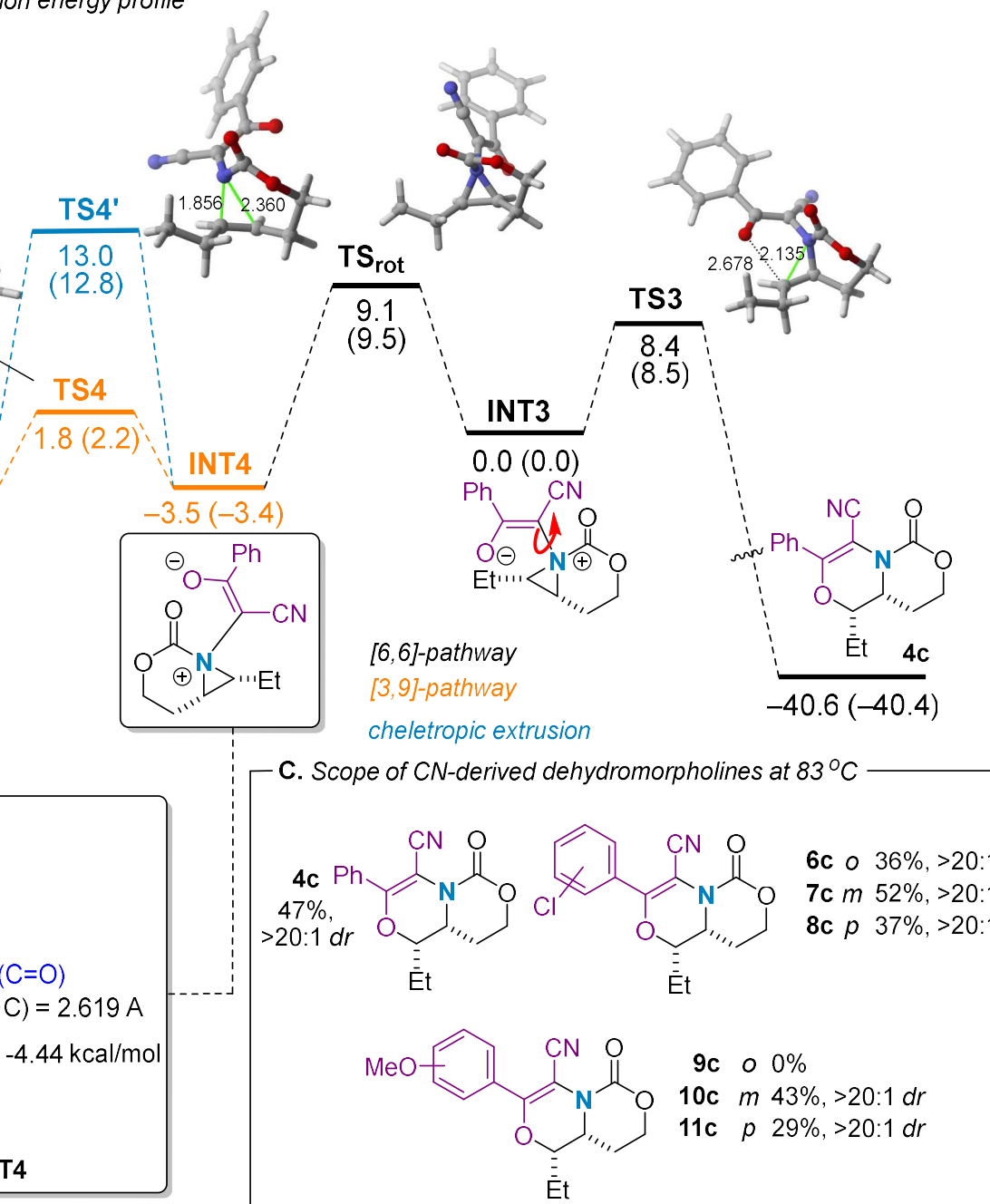

Scheme 3. A. Controlling product distribution using temperature. B. C. Computed reaction profile (relative free energies are given in $\mathrm{kcal} / \mathrm{mol})$ at the $\mathrm{SMD}\left(\mathrm{CH}_{2} \mathrm{Cl}_{2}\right) \mathrm{B} 3 \mathrm{LYP}-\mathrm{D} 3 / \mathrm{def} 2-\mathrm{SVP}$ level at $25^{\circ} \mathrm{C}$ and $83^{\circ} \mathrm{C}$ (values within parentheses) and contour plots of the reduced density gradient isosurfaces (density cutoff of 0.04 a.u.) for intermediate INT4. D. Scope of the process.

Employing higher temperatures with other cyano-derived diazoketones also proved fruitful (Scheme 3C). Ketones bearing ortho-, meta- and para-chlorosubstituted benzenes yielded 
dehydromorpholines $\mathbf{6 c - 8 c}$ in moderate yields and excellent $d r$ of $>20: 1$. The cyano group of dehydromorpholines $\mathbf{6 c - 8} \mathbf{c}$ is readily reduced to a primary amine for attaching these $\mathrm{N}$ heterocycles to a DNA headpiece for preparing DNA-encoded libraries, while the aryl chloride is an excellent functional handle for diversification of DELs. Ketones with meta- and paramethoxysubstituted benzenes were tolerated to furnish dehydromorpholines 10c and 11c in $43 \%$ and $29 \%$ yield, respectively. The ortho-substituted $9 \mathbf{c}$ was not obtained under these conditions, possibly due to steric congestion around the reactive site that prevents effective ylide formation.

Based on our computational analysis of [3,9]-aziridine formation in Figure 1A, strategies to prohibit NCI formation in the key ylide intermediate were envisaged to promote formation of the desired dehydromorpholines. We hypothesized that raising the barrier to $\mathrm{C}-\mathrm{N}$ bond rotation in the aziridinium ylide intermediate could 'trap' the kinetically formed conformer(s) and prevent formation of the NCI, potentially favoring a conformer similar to INT1 (Scheme 1A). To this end, the barriers for $\mathrm{C}-\mathrm{N}$ bond rotation in aziridinium ylides generated from reaction of $\mathbf{1}$ with donoracceptor and acceptor-acceptor carbene precursors 2a and 2d-f were calculated and compared (Figure 2). The results suggest that aziridinium ylides arising from reaction of $\mathbf{1}$

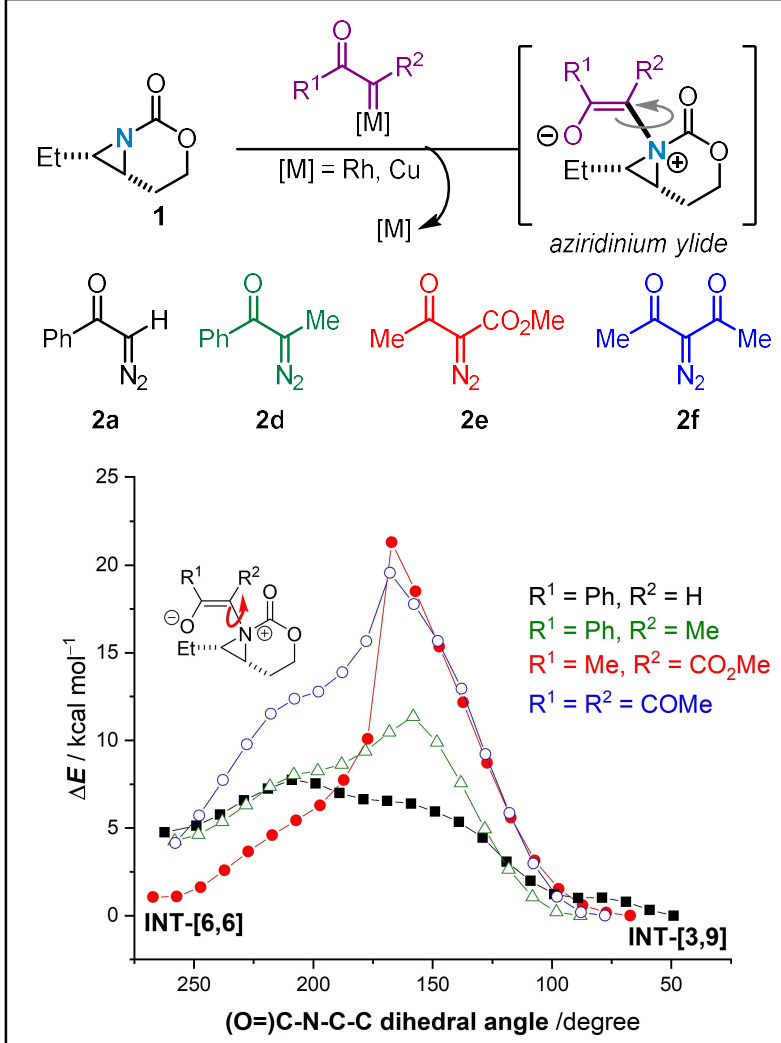

Figure 2. Computed barriers for $\mathrm{C}-\mathrm{N}$ bond rotation in aziridinium ylides from diverse carbene precursors.

with 2a (which experimentally give [3,9]-aziridines 3a, Scheme 1B) display a low barrier of ca. 7 
$\mathrm{kcal} / \mathrm{mol}$ to rotation about the $\mathrm{C}-\mathrm{N}$ bond (black line). The reaction of $\mathbf{1}$ with $\mathbf{2} \mathbf{b}$ revealed a higher barrier of $12 \mathrm{kcal} / \mathrm{mol}$ (green line) for $\mathrm{C}-\mathrm{N}$ bond rotation. In contrast, aziridinium ylides formed from reaction of $\mathbf{1}$ with dicarbonyl-containing diazo compounds $\mathbf{2 e}$ and $\mathbf{2 f}$ show significantly higher barriers to rotation around the $\mathrm{C}-\mathrm{N}$ bond at $\sim 23 \mathrm{kcal} / \mathrm{mol}$ (red line), and $20 \mathrm{kcal} / \mathrm{mol}$ (blue line), respectively. This increased rotational barrier may be attributed to the ability of the enolate of the ylide to be delocalized over both carbonyl-containing groups, providing additional structural rigidity and steric bulk that hinders the $\mathrm{C}-\mathrm{N}$ bond rotation.

To test this hypothesis, aziridine $\mathbf{1}$ was treated with methylacetoacetate-derived $\mathbf{2 e}$ and catalytic $\mathrm{Rh}_{2}(\mathrm{OAc})_{4}$ under optimized conditions (Scheme 4A, see Supporting Information for details). The dehydromorpholine $4 \mathbf{e}$ was obtained in $38 \%$ yield ( $48 \%$ by NMR), accompanied by the corresponding cheletropic extrusion product $5 \mathbf{e}$ ( $42 \%$ by NMR). Interestingly, no competing [3,9]-aziridine 3e was observed in the crude mixture. Computational analysis of this reaction (Scheme 4D) revealed the $\mathrm{O} \cdots \mathrm{C}(=\mathrm{O})$ distance is much longer for INT6 (3.085 $\AA$ ) than for INT1 $(2.530 \AA)$, a distance close to the limit of the sum of the van der Waals radii $(3.22 \AA)$. The longer distance is presumably required to accommodate the second $\mathrm{C}=\mathrm{O}$ from the acceptor-acceptor carbene. This is reflected in the low computed stabilization energy $\left(\Delta \mathrm{E}^{(2)}\left(\mathrm{LP}(\mathrm{O}) \rightarrow \pi^{*}(\mathrm{C}=\mathrm{O})\right)=\right.$ $-0.50 \mathrm{kcal} / \mathrm{mol}$ ) which can be considered negligible. This effectively prevents formation of the undesired NCI; as a result, INT6 and INT5 are nearly degenerate ( $\Delta \Delta \mathrm{G} \sim 1 \mathrm{kcal} / \mathrm{mol})$, a markedly different scenario from that involving INT1/INT2 ylides (Figure 1A, vide supra). Although this computational data presents a reasonable scenario for the 1:1 product mixture, we were puzzled why no $3 \mathbf{e}$ was observed, considering the predicted energy barrier is only $5.3 \mathrm{kcal} / \mathrm{mol}$ compared to $15.6 \mathrm{kcal} / \mathrm{mol}$ for $\mathbf{5 e}$ (Scheme 4D). A variety of potential pathways were considered. One possibility invoked a retro-hetero-Diels-Alder reaction of $4 \mathbf{e}$ to give $5 \mathbf{e}$; however, re-exposing $4 \mathbf{e}$ 
under the standard reaction conditions (Scheme 4C) gave only recovered 4e. Alternatively, 5e might arise from a retro-hetero-Diels-Alder of a product formed by attack of the ester carbonyl on the aziridinium ylide via delocalization of the negative charge in INT6. However, computational

A. Reaction discovery: competitive cheletropic extrusion and cyclization

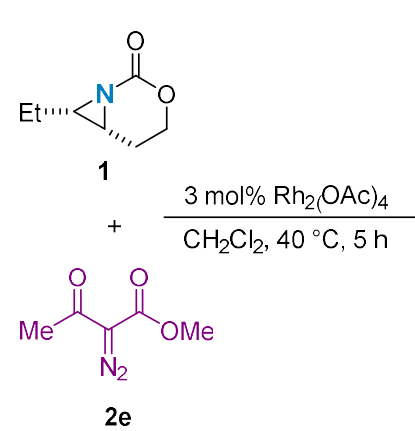

$2 e$

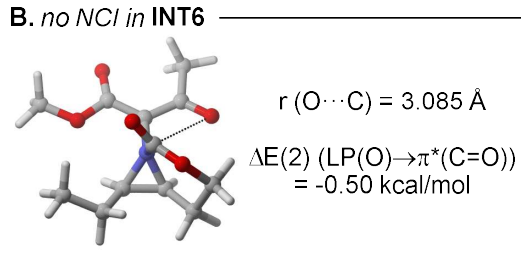

D. Reaction energy profile
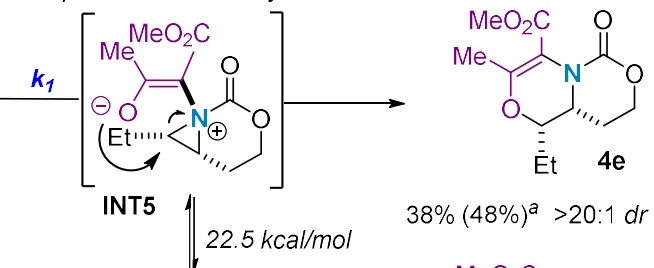

$38 \%(48 \%)^{a}>20: 1 d r$
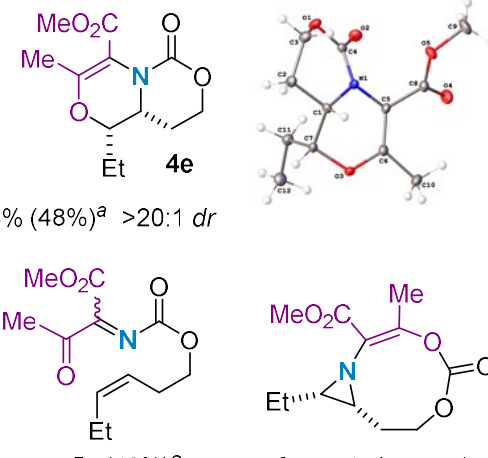

5e $(42 \%)^{a}$

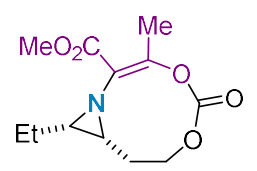

3e not observed
INT6

C. Control experiment-
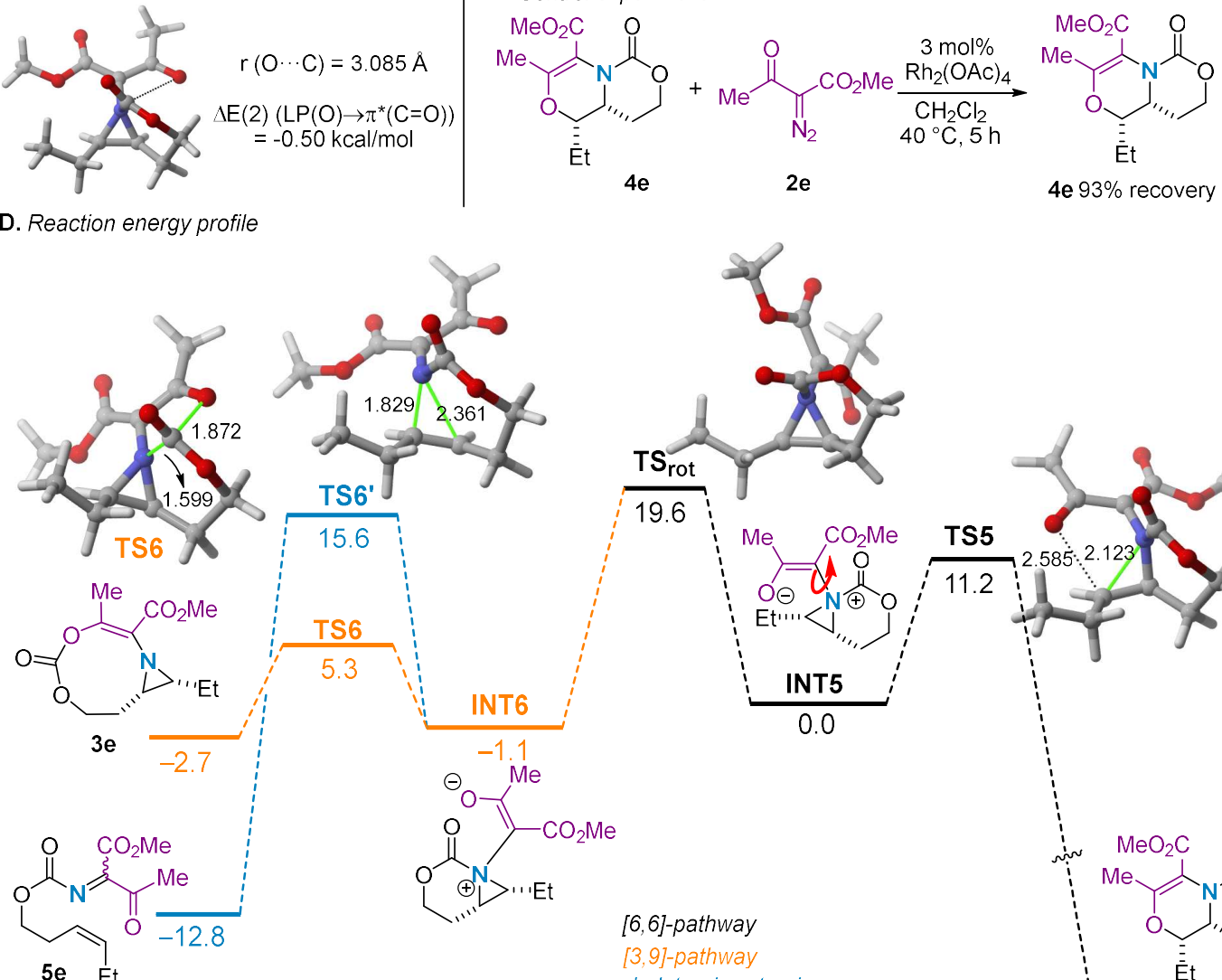

$-1.1$

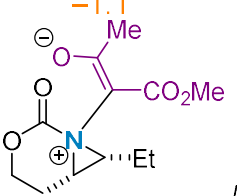

[6,6]-pathway

[3,9]-pathway

cheletropic extrusion

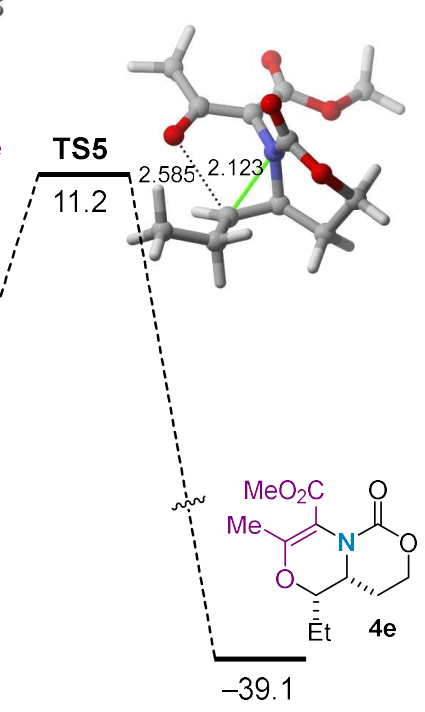

Scheme 4. Competing cheletropic extrusion/ring expansion to dehydromorpholines. See caption to Figure 1 for computational details. 
analysis argues against this pathway, as it shows an energy barrier of $18.9 \mathrm{kcal} / \mathrm{mol}$ (see Figure S15 in the Supporting Information).

To experimentally interrogate the origin of 5e, NMR time-course data was collected to identify long-lived reaction intermediates or other products not observed in the final crude mixture. The data (Figure 3) showed a consistent increase in product $4 \mathrm{e}$ over the $4 \mathrm{~h}$ reaction period. Interestingly, a small amount of 3e was noted, which increased from 1-2 $\mathrm{h}$, then decreased from 2-4 h, at which time the cheletropic extrusion product 5e was observed. The $2 \mathrm{~h}$ reaction aliquot was further analyzed by 1D TOCSY (see Figure S-9 in the Supporting Information), which revealed a unique spin system corresponding to $\mathbf{3 e}$. These data are the first experimental evidence supporting the conclusion that the reaction is under thermodynamic control (vide supra), where the $[3,9]$-aziridine $\mathbf{3 e}$ gives rise to $\mathbf{5 e}$. This result is further supported by the computational data,

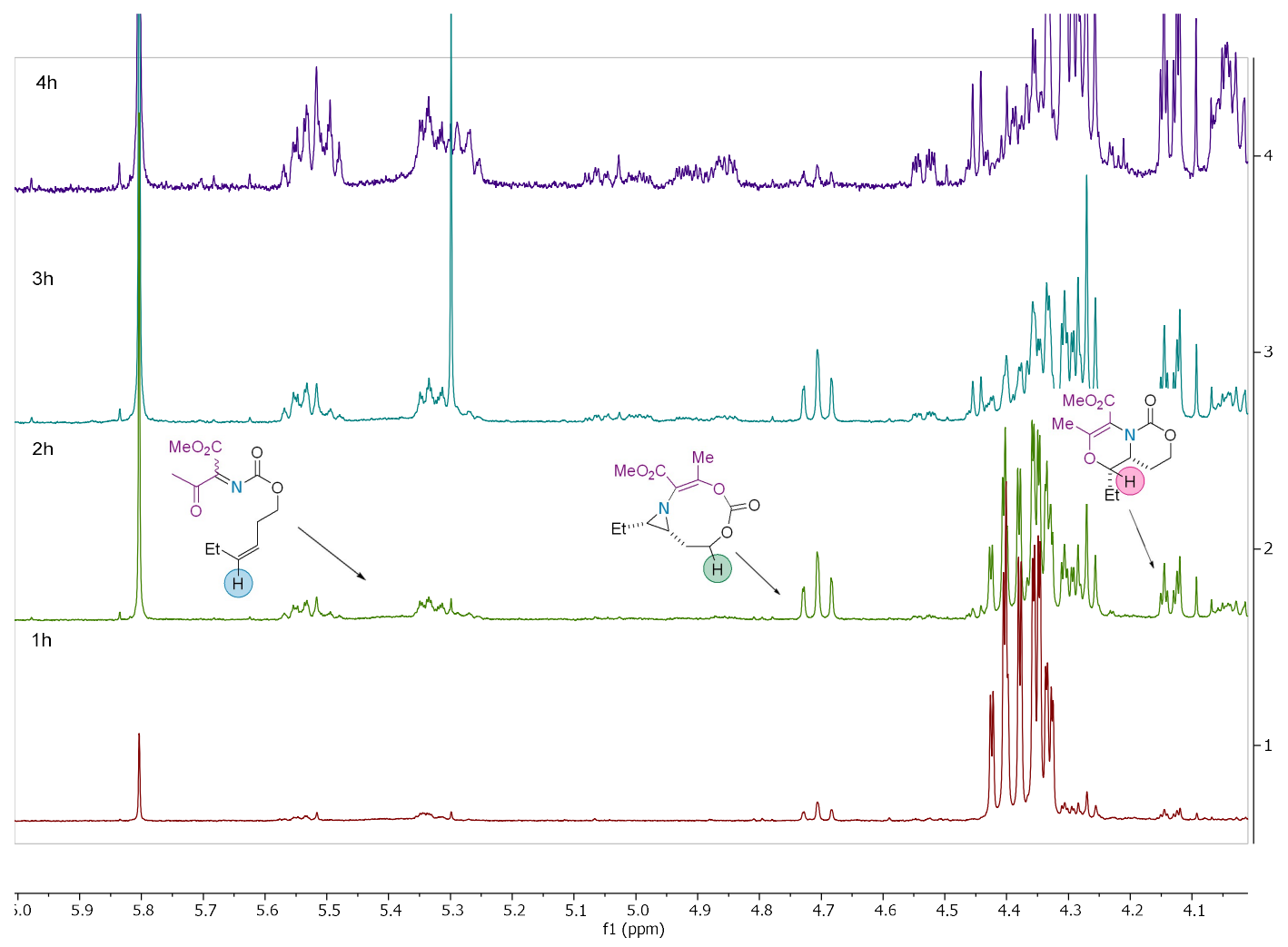

Figure 3. ${ }^{1} \mathrm{H}$ NMR time course data for the reaction of $\mathbf{1}$ and $\mathbf{2 e .}$ 
which show that the formation of $\mathbf{3 e}$ from INT-6 is reversible in view of the low computed reaction and barrier energies (1.6 and $8.0 \mathrm{kcal} / \mathrm{mol}$, respectively, see Scheme 4D).

Our combined computational and experimental evidence suggests that divergent reactivity to give a $\sim 1: 1$ mixture of $\mathbf{4 e}$ and $\mathbf{5 e}$ is due to the non-Curtin-Hammett kinetic formation of aziridinium ylide conformers INT5 and INT6 (Scheme 4A). INT5 contains a syn-relationship between the enolate of the methyl ketone and the external aziridine $\mathrm{C}-\mathrm{N}$ bond, which represents the correct geometry for dehydromorpholine formation. The other potential aziridinium ylide INT6 does not display the correct orientation, and thus initially forms $\mathbf{3 e}$, which is ultimately converted to $5 \mathbf{e}$.

Our attempts to utilize non-symmetric acceptor-acceptor diazo carbene precursors to form dehydromorpholines highlighted the importance of steric effects, rotational barriers around the $\mathrm{C}-$ $\mathrm{N}$ bond of the aziridinium ylide and NCIs in determining the reaction outcome. Symmetric diketone-containing carbene precursors, such as $\mathbf{2} \mathbf{f}$ (Scheme 5A), mitigated these complications by yielding only a single ylide intermediate that engages in nucleophilic ring-opening of the aziridinium ylide to form the dehydromorpholine. A series of cis-substituted aziridines bearing linear alkyl chains, including a primary alkyl chloride, furnished $\mathbf{4 f}$ and $\mathbf{1 2 f} \mathbf{- 1 4 f}$ as the sole products in moderate yields and high $d r$ of $>20: 1$. Isopropyl-substituted aziridine $\mathbf{1 4}$ was tolerated to furnish 14f, albeit in moderate yield, indicating the sensitivity of the reaction to steric effects. Small amounts of cheletropic extrusion product $(\sim 8 \%)$ were also observed in reactions of branched aziridines. Enantiopure benzyl-substituted aziridine $(S, R)-15$, obtained in $94 \% e e$, was subjected to the reaction conditions; the product $\mathbf{1 5 f}$ was obtained in 39\% yield and an excellent $>20: 1 d r$. Importantly, the $97 \%$ ee of $\mathbf{1 5 f}$ (Scheme 5B) highlighted our ability to effectively transfer stereochemical information from the aziridine into the products to furnish enantioenriched $\mathrm{N}$ - 
heterocycles for future efforts in DEL synthesis. This experimental result also excludes the possibility of a [4+2] hetero-Diels-Alder reaction being the operative mechanism that leads to the dehydromorpholine products $\mathbf{4 f}$ and $\mathbf{1 2 f - 1 5 f}$ (Schemes 5A-B).

This chemistry was not restricted to aziridines bearing a 6-membered bicyclic tether; a [5,3]-bicyclic aziridine 17 was capable of yielding the substituted dehydromorpholine $\mathbf{1 8}$ (Scheme 5C). A nice feature of this chemistry was the ability to carry out the reaction in a telescoped fashion directly from the pre-oxidized nitrene precursor 16 to deliver 18 in $47 \%$ yield and $>20: 1 d r$ over
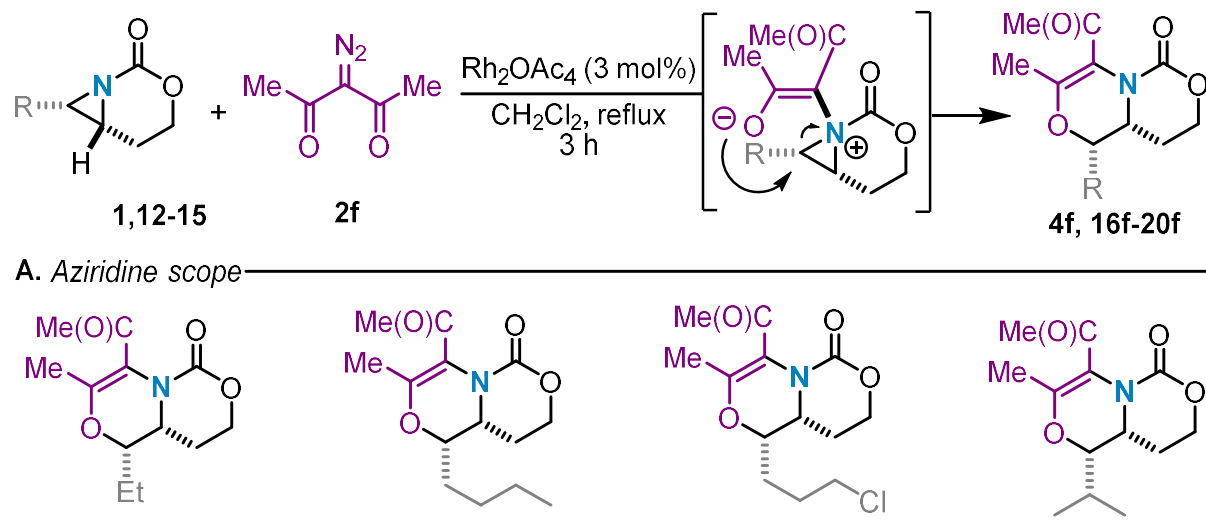

$4 f$

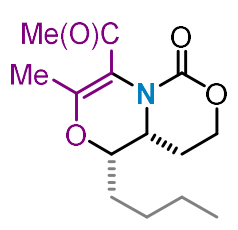

$12 f$

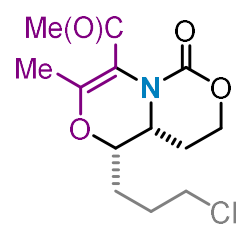

$13 f$

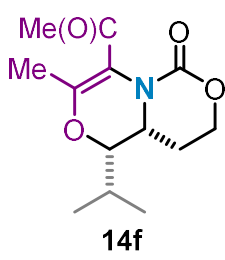

$48 \%{ }^{\mathrm{a}},>20: 1 d r$

$58 \%{ }^{\mathrm{a}},>20: 1 d r$

$58 \%{ }^{\mathrm{a}},>20: 1 d r$

$51 \%^{\mathrm{a}},>20: 1 d r$

$$
3 \mathrm{~h} \text {. }
$$

B. Enantiotransfer experiment to yield $(\mathrm{S}, \mathrm{R})-\mathbf{1 5 f}$

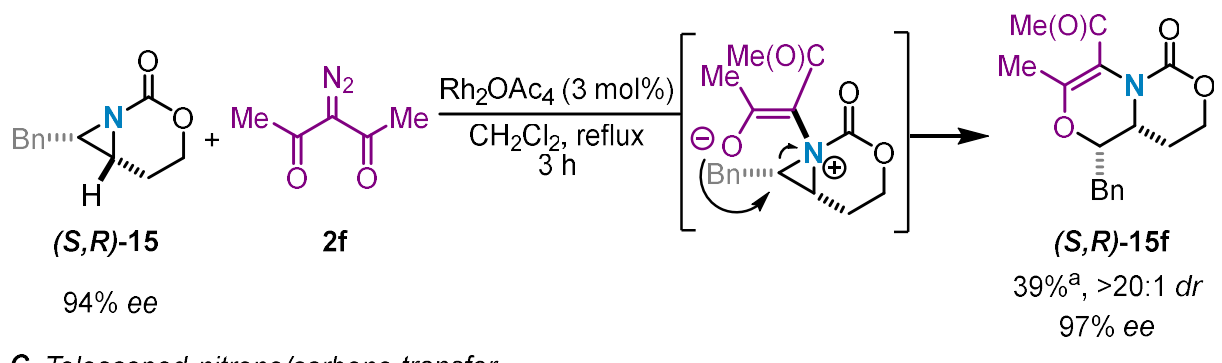

C. Telescoped nitrene/carbene transfer $\%^{a},>20: 1 d r$

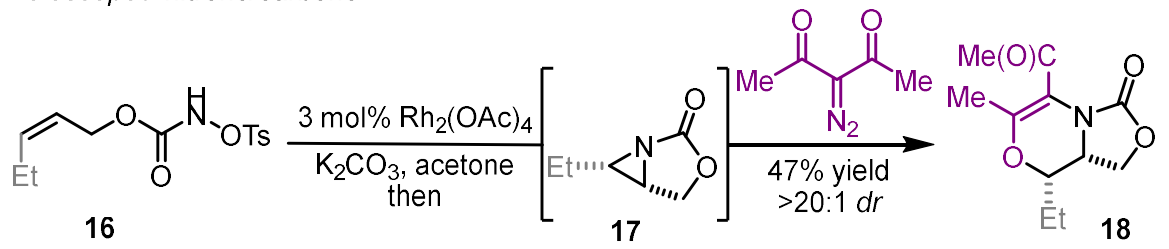

Scheme 5. Dehydromorpholine formation from symmetric carbene precursors. 
both the aziridination and the ring expansion steps. Expansion of the telescoped reaction to more sterically demanding symmetric and unsymmetric carbene precursors with 1 proved challenging, highlighting the sensitivity of this transformation to sterics (see the Supporting Information for further details). Efforts are ongoing to address this limitation.

\section{CONCLUSION}

In conclusion, we have demonstrated a new method for the synthesis of highly substituted dehydromorpholines through the intermediacy of aziridinium ylides. The development of this chemistry has enabled the extension of aziridinium ylide chemistry to the concomitant formation of both a $\mathrm{C}-\mathrm{N}$ and a $\mathrm{C}-\mathrm{O}$ bond in a manner that preserves the stereochemical information embedded in the substrate aziridine. The chemistry is tolerant of a wide range of functionalities that we will employ for attachment to DNA in DEL synthesis to prepare diverse libraries of heterocycles with useful bioactivity. In addition, we have uncovered several key insights that describe the importance of steric effects, rotational barriers around the $\mathrm{C}-\mathrm{N}$ bond of the aziridinium ylide, and NCIs on the ultimate reaction outcome. These critical insights will assist in the further development of this chemistry to generate novel and complex $N$-heterocycles that will further expand complex amine chemical space.

\section{ASSOCIATED CONTENT}

Supporting Information. Experimental procedures, computational details, and characterization data for all new compounds are available in the Supporting Information. X-ray crystallographic information is available for 3a (CDCC Deposition Number 2124058) and 4e (2124059). This material is available free of charge via the Internet at http://pubs.acs.org. 
The following files are available free of charge.

Supplementary Information (PDF)

\section{AUTHOR INFORMATION}

\section{Corresponding Author}

*schomakeri@chem.wisc.edu; *israel@quim.ucm.es

\section{Author Contributions}

The manuscript was written through contributions of all authors. All authors have given approval to the final version of the manuscript.

\section{Funding Sources}

J.M.S. thanks the NIH 1R01GM132300-01 for support of this work. The NMR facilities at UWMadison are funded by the National Science Foundation (NSF; CHE-9208463, CHE-9629688) and National Institutes of Health (NIH; RR08389-01). The Q-Exactive mass spectrometer was acquired from an NIH-S10 award (NIH-1S10OD020022-1). The Bruker D8 VENTURE Photon III X-ray diffractometer was partially funded by NSF Award \#CHE-1919350 to the UW-Madison Department of Chemistry. Bruker Quazar APEX2 was purchased by UW-Madison Department of Chemistry with a portion of a generous gift from Paul J. and Margaret M. Bender. I.F. acknowledges financial support from the Spanish MCIN/AEI/10.13039/501100011033 (Grants PID2019-106184GB-I00 and RED2018-102387-T).

\section{ACKNOWLEDGMENT}


Dr. Charlie Fry and Dr. Heike Hoffstetter of the University of Wisconsin-Madison are thanked

for assistance with NMR spectroscopy, while Dr. Martha Vestling of UW-Madison is thanked

for her assistance with collecting MS data. Amelia M. Wheaton is thanked for help with

processing X-ray crystallographic data.

\begin{abstract}
ABBREVIATIONS
$d r$, diastereomeric ratio; $e e$, enantiomeric excess; INT, intermediate; NCI, non-covalent interaction; DFT, density functional theory; VT, variable temperature; DEL, DNA encoded library; LP, lone pair; SOPT, second order perturbation theory; NBO, natural bond orbital, TOCSY; total correlation spectroscopy.
\end{abstract}

\title{
REFERENCES
}

1. Dequina, H. J.; Nicastri, K. A.; Schomaker, J. M. Chapter One - Additions of N, O, and S Heteroatoms to Metal-Supported Carbenes: Mechanism and Synthetic Applications in Modern Organic Chemistry. In Advances in Organometallic Chemistry; Pérez, P. J., Ed.; Academic Press, 2021; Vol. 76, pp 1-100. https://doi.org/10.1016/bs.adomc.2021.04.001.

2. Doyle, M. P. 5.2 - Transition Metal Carbene Complexes: Diazodecomposition, Ylide, and Insertion. In Comprehensive Organometallic Chemistry II; Abel, E. W., Stone, F. G. A., Wilkinson, G., Eds.; Elsevier: Oxford, 1995; pp 421-468. https://doi.org/10.1016/B978$\underline{008046519-7.00117-9 .}$.

3. Gillingham, D.; Fei, N. Catalytic X-H Insertion Reactions Based on Carbenoids. Chem. Soc. Rev. 2013, 42 (12), 4918-4931. https://doi.org/10.1039/C3CS35496B.

4. Jana, S.; Guo, Y.; Koenigs, R. M. Recent Perspectives on Rearrangement Reactions of Ylides via Carbene Transfer Reactions. Chemistry - A European Journal 2021, 27 (4), 1270-1281. https://doi.org/10.1002/chem.202002556.

5. Sweeney, J. B. Sigmatropic Rearrangements of 'Onium' Ylids. Chem. Soc. Rev. 2009, 38 (4), 1027-1038. https://doi.org/10.1039/B604828P.

6a. Kaiser, D.; Klose, I.; Oost, R.; Neuhaus, J.; Maulide, N. Bond-Forming and -Breaking Reactions at Sulfur(IV): Sulfoxides, Sulfonium Salts, Sulfur Ylides, and Sulfinate Salts. Chem. Rev. 2019, 119 (14), 8701-8780. https://doi.org/10.1021/acs.chemrev.9b00111. 
6b. Zhang, Y.; Wang, J. Catalytic [2,3]-Sigmatropic Rearrangement of Sulfur Ylide Derived from Metal Carbene. Coordination Chemistry Reviews 2010, 254 (9), 941-953. https://doi.org/10.1016/j.ccr.2009.12.005. 6c. N. Lakeev, S.; O. Maydanova, I.; Z. Galin, F.; A. Tolstikov, G. Sulfur Ylides in the Synthesis of Heterocyclic and Carbocyclic Compounds. Russ. Chem. Rev. 2001, 70 (8), 655-672. https://doi.org/10.1070/RC2001v070n08ABEH000645.

6d. Magdesieva, N. N.; Sergeeva, T. A. Use of Sulfonium Ylides in the Synthesis of Heterocyclic Systems (Review). Chemistry of Heterocyclic Compounds 1990, 26 (2), 123-145. https://doi.org/10.1007/BF00499405.

7. Murphy, G. K.; West, F. G. Oxonium Ylide Rearrangements in Synthesis. In Molecular Rearrangements in Organic Synthesis; John Wiley \& Sons, Ltd, 2015; pp 497-538. https://doi.org/10.1002/9781118939901.ch16.

8a. Roiser, L.; Zielke, K.; Waser, M. Ammonium Ylide Mediated Cyclization Reactions. Asian Journal of Organic Chemistry 2018, 7 (5), 852-864. https://doi.org/10.1002/ajoc.201800091.

8b. Vanecko, J. A.; Wan, H.; West, F. G. Recent Advances in the Stevens Rearrangement of Ammonium Ylides. Application to the Synthesis of Alkaloid Natural Products. Tetrahedron 2006, 62 (6), 1043-1062. https://doi.org/10.1016/j.tet.2005.09.123.

9. Sheng, Z.; Zhang, Z.; Chu, C.; Zhang, Y.; Wang, J. Transition Metal-Catalyzed [2,3]Sigmatropic Rearrangements of Ylides: An Update of the Most Recent Advances. Tetrahedron 2017, 73 (29), 4011-4022. https://doi.org/10.1016/j.tet.2016.11.045.

10a. Dequina, H. J.; Schomaker, J. M. Aziridinium Ylides: Underused Intermediates for Complex Amine Synthesis. Trends in Chemistry 2020, 2 (10), 874-887. https://doi.org/10.1016/j.trechm.2020.08.003. 10b. Ranjith, J.; Ha, H.-J. Synthetic Applications of Aziridinium Ions. Molecules 2021, 26, 1774.

11a. Gironda-Martínez, A.; Donckele, E. J.; Samain, F.; Neri, D. DNA-Encoded Chemical Libraries: A Comprehensive Review with Succesful Stories and Future Challenges. ACS Pharmacol. Transl. Sci. 2021, 4 (4), 1265-1279. https://doi.org/10.1021/acsptsci.1c00118.

11b. Kleiner, R. E.; Dumelin, C. E.; Liu, D. R. Small-Molecule Discovery from DNA-Encoded Chemical Libraries. Chem. Soc. Rev. 2011, 40 (12), 5707-5717. https://doi.org/10.1039/C1CS15076F. 11c. Martín, A.; Nicolaou, C. A.; Toledo, M. A. Navigating the DNA Encoded Libraries Chemical Space. Communications Chemistry 2020, 3 (1), 127. https://doi.org/10.1038/s42004-020-00374-1.

12a. de Loera, D.; Liu, F.; Houk, K. N.; Garcia-Garibay, M. A. Aziridine Nitrogen Inversion by Dynamic NMR: Activation Parameters in a Fused Bicyclic Structure. J. Org. Chem. 2013, 78 (22), 11623-11626. https://doi.org/10.1021/j04022315. 12b. Anet, F. A. L.; Osyany, J. M. Nuclear Magnetic Resonance Spectra and Nitrogen Inversion in 1-Acylaziridines. J. Am. Chem. Soc. 1967, 89 (2), 352-356. https://doi.org/10.1021/ja00978a032. 12c. Bottini, A. T.; Roberts, J. D. Nuclear Magnetic Resonance Spectra. Nitrogen Inversion Rates of N-Substituted Aziridines (Ethylenimines)1. J. Am. Chem. Soc. 1958, $80 \quad$ (19), 5203-5208. https://doi.org/10.1021/ja01552a048. 
13. Clark, J. S.; Hodgson, P. B.; Goldsmith, M. D.; Blake, A. J.; Cooke, P. A.; Street, L. J. Rearrangement of Ammonium Ylides Produced by Intramolecular Reaction of Catalytically Generated Metal Carbenoids. Part 2. Stereoselective Synthesis of Bicyclic Amines. J. Chem. Soc., Perkin Trans. 1 2001, No. 24, 3325-3337. https://doi.org/10.1039/B108182A.

14. Rowlands, G. J.; Kentish Barnes, W. Studies on the [2,3]-Stevens Rearrangement of Aziridinium Ions. Tetrahedron Letters 2004, $45 \quad$ (28), 5347-5350. https://doi.org/10.1016/j.tetlet.2004.05.087.

15. Hata, Y.; Watanabe, M. Fragmentation Reaction of Aziridinium Ylids. II. Tetrahedron Letters 1972, 13 (46), 4659-4660. https://doi.org/10.1016/S0040-4039(01)94391-6.

16a. Ju, M.; Weatherly, C. D.; Guzei, I. A.; Schomaker, J. M. Chemo- and Enantioselective Intramolecular Silver-Catalyzed Aziridinations. Angewandte Chemie International Edition 2017, 56 (33), 9944-9948. https://doi.org/10.1002/anie.201704786. 16b. Rigoli, J. W.; Weatherly, C. D.; Alderson, J. M.; Vo, B. T.; Schomaker, J. M. Tunable, Chemoselective Amination via Silver Catalysis. J. Am. Chem. Soc. 2013, 135 (46), 17238-17241. https://doi.org/10.1021/ja406654y. 16c. Rigoli, J. W.; Weatherly, C. D.; Vo, B. T.; Neale, S.; Meis, A. R.; Schomaker, J. M. Chemoselective Allene Aziridination via Ag(I) Catalysis. Org. Lett. 2013, 15 (2), 290-293. https://doi.org/10.1021/ol303167n.

17. Rauk, A.; Allen, L. C.; Mislow, K. Pyramidal Inversion. Angewandte Chemie International Edition in English 1970, 9 (6), 400-414. https://doi.org/10.1002/anie.197004001.

18. Couch, J. F. ISOLATION OF SPARTEINE FROM LUPINUS BARBIGER (WATSON). $J$. Am. Chem. Soc. 1932, 54 (4), 1691-1692. https://doi.org/10.1021/ja01343a504.

19. Tröger, J. Ueber Einige Mittelst Nascirenden Formaldehydes Entstehende Basen. Journal für Praktische Chemie 1887, 36 (1), 225-245. https://doi.org/10.1002/prac.18870360123.

20a. Schmid, S. C.; Guzei, I. A.; Schomaker, J. M. A Stereoselective [3+1] Ring Expansion for the Synthesis of Highly Substituted Methylene Azetidines. Angewandte Chemie International Edition 2017, 56 (40), 12229-12233. https://doi.org/10.1002/anie.201705202. 20b.Schmid, S. C.; Guzei, I. A.; Fernández, I.; Schomaker, J. M. Ring Expansion of Bicyclic Methyleneaziridines via Concerted, Near-Barrierless [2,3]-Stevens Rearrangements of Aziridinium Ylides. ACS Catal. 2018, 8 (9), 7907-7914. https://doi.org/10.1021/acscatal.8b02206.

21.Eshon, J.; Nicastri, K. A.; Schmid, S. C.; Raskopf, W. T.; Guzei, I. A.; Fernández, I.; Schomaker, J. M. Intermolecular [3+3] Ring Expansion of Aziridines to Dehydropiperidines through the Intermediacy of Aziridinium Ylides. Nature Communications 2020, 11 (1), 1273. https://doi.org/10.1038/s41467-020-15134-X.

22. L.; Liu, Q.-B.; Wang, D.-S.; Li, X.; Han, X.-W.; Xiao, W.-J.; Zhou, Y.-G. Tandem RingOpening/Closing Reactions of N-Ts Aziridines and Aryl Propargyl Alcohols Promoted by tBuOK. Org. Lett. 2009, 11 (5), 1119-1122. https://doi.org/10.1021/ol802862p. 
23. Zhang, S.; Shan, C.; Zhang, S.; Yuan, L.; Wang, J.; Tung, C.-H.; Xing, L.-B.; Xu, Z. Breaking Aziridines to Construct Morpholines with a Gold(i)-Catalyzed Tandem Ring-Opening and Cycloisomerization Reaction. Org. Biomol. Chem. 2016, 14 (46), 10973-10980. https://doi.org/10.1039/C6OB02284G.

24. Fang, S.; Zhao, Y.; Li, H.; Zheng, Y.; Lian, P.; Wan, X. [3 + 3]-Cycloaddition of $\alpha$ Diazocarbonyl Compounds and N-Tosylaziridines: Synthesis of Polysubstituted 2H-1,4-Oxazines through Synergetic Catalysis of AgOTf/Cu(OAc)2. Org. Lett. 2019, 21 (7), 2356-2359. https://doi.org/10.1021/acs.orglett.9b00632.

25. Gautrot, J. E.; Hodge, P.; Cupertino, D.; Helliwell, M. Experimental Evidence for Carbonyl$\pi$ Electron Cloud Interactions. New J. Chem. 2006, 30 (12), 1801-1807. https://doi.org/10.1039/B608628D.

\section{Table of Contents Graphic}

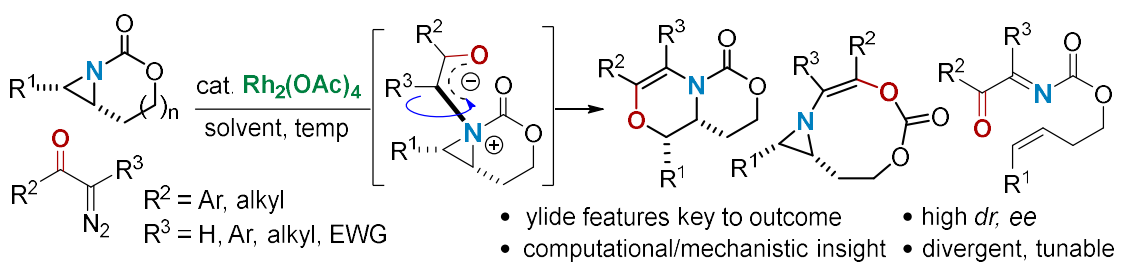

